\title{
NGHIÊN CỨU MẬT Độ XƯƠNG Ở BỆNH NHÂN BỆNH PHỔI TẮC NGHẼN MÃN TÍNH
}

Hoàng Vĩnh Trung Hiếu, Hoàng Thị Lan Hương, Hoàng Vĩnh Phú Phan Thị Thúy, Nguyễn Thị Minh Huệ Khoa Nội A-Bệnh viện TW Huế CS2

DOI: $10.47122 / v j d e .2020 .39 .8$

\section{ABSTRACT}

Background: Osteoporosis is one of the major extra-pulmonary manifestations of chronic obstructive pulmonary disease (COPD), which due to fermoral neck fractures, vertebral compression fractures, impacts on the quality of life. This study was undertaken to determine the bone mineral density (BMD) in COPD patients and evaluate association, correlation between BMD and other factors. Materials and Methods: This cross-sectional study was conducted in 42 patients which diagnosed COPD (GOLD 2015 guidelines). After a detailed clinical history (age, sex, packs-year of smoking, bmi, duration of disease, glucocorticoids use), spirometry was done to stage the severity of FEV1. DEXA scan was performed to determine osteoporosis (WHO's criteria). Statistical analysis methods was description, compare means, bivariate correlation, univariate logistic analysis, were performed by SPSS 16.0. Results: A total of 42 COPD patients were included. Twenty-one patients $(50,0 \%)$ had osteoporosis and nine $(18.6 \%)$ had osteopenia. There was also significant difference in BMD among normal, osteopenia, and osteoporosis group. BMD had associated with sex, glucocorticoids use and significantly correlated with age, bmi, duration of disease, FEV1. Otherwise, there had not been correlation between BMD and smoking. Conclusions: COPD patients had low BMD and high risk of osteoporosis Therefore, BMD should be been in COPD management profile.

Keywords: bone mineral density, osteoporosis, COPD

\section{TÓM TẮT}

Tổng quan: Loãng xương là một trong những biểu hiện chủ yếu ngoài phổi của bệnh phổi tắc nghẽn mãn tính, gây ra những biến chứng như gãy cổ xương đùi, xẹp đốt sống... làm ảnh hưởng đến chất lượng cuộc sống. Nghiên cứu này được thực hiện với mục tiêukhảo sát mật độ xương ở bệnh nhân bệnh phổi tắc nghẽn mãn tính và đánh giá mối liên quan, tương quan giữa mật độ xương với một số yếu tố khác. Đối tượng và phương pháp: Nghiên cứu mô tả cắt ngang thực hiện trên 42 bệnh nhân bệnh phổi tắc nghẽn mãn tính khám và điều trị tại Bệnh viện Trung ương Huế Cơ sở 2 trong năm 2017. Bệnh nhân được chẩn đoán theo GOLD 2015 và xác định tuổi, giới, BMI, tiền sử bệnh, đo chức năng hô hấp đánh giá FEV1, đo mật độ xương theo phương pháp DEXA đánh giá mật độ xương theo tiêu chuẩn của WHO. Phân tích mô tả, so sánh trung bình, tương quan, hồi quy đơn biến được thực hiện. Kết quả: 42 bệnh nhân bệnh phổi tắc nghẽn mãn tính tuổi từ $44-90$ có $28,57 \%$ bệnh nhân bình thường, $21,43 \%$ bệnh nhân thiếu xương và đặc biệt $50 \%$ bệnh nhân loãng xương. Phần lớn bệnh nhân loãng xương có FEV1 từ 30$80 \%$. Mật độ xương liên quan và tương quan với giới, tuổi, tình trạng sử dụng corticoid, BMI, thời gian mắc và $\operatorname{FEV} 1(\mathrm{p}<0,05)$. Chưa có sự tương quan giữa mật độ xương với mức độ hút thuốc lá (p>0,05). Kết luận: Bệnh nhân bệnh phổi tắc nghẽn mãn tính có mật độ xương giảm, tỷ lệ loãng xương cao. Đo mật độ xương cần xem xét đưa vào vấn đề cần được quản lý ở bệnh phổi tắc nghẽn mãn tính.

Tù khóa: mật độ xuơng, loãng xuơng, bệnh phổi tắc nghẽn mãn tính

Chịu trách nhiệm chính: Hoàng Vĩnh Trung Hiếu

Ngày nhận bài: 10/3/2020

Ngày phản biện khoa học: 14/3/2020 
Ngày duyệt bài: 16/4/2020

Email: dr.mr.christiano@gmail.com

ĐT: 0987.313789

\section{1. ĐẠT VẤN ĐỀ}

Bệnh phổi tắc nghẽn mãn tính là một vấn đề sức khỏe của toàn cầu. Trung bình $5-15 \%$ dân số người trưởng thành ở các nước công nghiệp phát triển mắc bệnh phổi tắc nghẽn mãn tính. Theo nghiên cứu dịch tễ học về bệnh phổi tắc nghẽn mãn tính ở 12 nước Châu Á Thái Bình Dương cho thấy tî lệ bệnh phổi tắc nghẽn mãn tính ở Việt Nam là cao nhất với $6,7 \%[1]$.

Những năm gần đây trên thế giới cũng như nước ta đã có nhiều công trình nghiên cứu bệnh phổi tắc nghẽn mãn tính như về nguyên nhân, phân độ, biến chứng và đặc biệt là các bệnh đồng mắc nhằm đưa ra những chiến lược phòng chống, điều trị và quản lý bệnh này.

Trong số đó, một bệnh đồng mắc và cũng có thể xem biến chứng, biểu hiện ngoài phổi của bệnh phổi tắc nghẽn mãn tính là loãng xương. Hiện nay loãng xương đang là vấn đề thời sự trên toàn thế giới bởi biểu hiện bên ngoài rất nhẹ nhàng nhưng ẩn dấu bên trong sự tàn phá đối với người bệnh. Đặc biệt gây nên biến chứng gãy xương nhất là gãy xương đùi, xẹp đốt sống.

Có nhiều yếu tố nguy cơ gây loãng xương ở bệnh nhân bệnh phổi tắc nghẽn mãn tính như hút thuốc lá, thiếu vitamin $\mathrm{D}$, giảm chỉ số khối cơ thể, suy sinh dục, giảm vận động, sử dụng corticosteroid và yếu tố viêm hệ thống.

Dự báo tới năm 2050, toàn thế giới sẽ có tới 6,3 triệu trường hợp gãy cổ xương đùi do loãng xương, $51 \%$ số này ở châu Á, trong đó có Việt Nam. Trong một nghiên cứu trước đây chỉ ra rằng nguy cơ loãng xương tăng gấp đôi ở những bệnh nhân bệnh phổi tắc nghẽn mãn tính [2].

Để góp phần tìm hiểu về bệnh phổi tắc nghẽn mãn tính, chúng tôi tiến hành nghiên cứu một khía cạnh khác của bệnh đó là loãng xương. Do đó chúng tôi thực hiện nghiên cứu này với mục tiêu: Khảo sát mật độ xương ở bệnh nhân bệnh phổi tắc nghẽn mãn tính và đánh giá mối liên quan, tuoong quan giữa mật độ xương với tuổi, mức độ hút thuốc lá, chi số khối co thể, thời gian bi bệnh, sư dụng corticosteroid, FEVI.

\section{2. ĐỐI TƯợNG VÀ PHƯƠNG PHÁP NGHIÊN CÚU}

2.1. Đối tượng nghiên cứu

Gồm 42 bệnh nhân BPTNMT khám và điều trị tại Bệnh viện Trung ương Huế Cơ sở 2 từ tháng 03/2017 đến tháng 11/2017.

\section{Tiêu chuẩn chọn bệnh}

Những bệnh nhân đã được chẩn đoán BPTNMT theo GOLD 2015và đồng ý tham gia nghiên cứu.

\section{Tiêu chuẩn loại trù̀}

Chúng tôi loại trừ các đối tượng:

- Những bệnh nhân có giảm FEV1 nhưng không phải BPTNMT.

- Các bệnh lý kèm theo: suy thận mãn, hội chứng thận hư, viêm khớp dạng thấp, viêm cột sống dính khớp, ung thư phổi, các loại ung thư di căn xương...

- Tiền sử phẫu thuật dạ dày, cắt đoạn ruột, hội chứng kém hấp thu. hô hấp.

- Bệnh nhân không đo được chức năng

\subsection{Phương pháp nghiên cứu}

\section{Thiết kế nghiên cứu}

Dùng phương pháp nghiên cứu mô tả cắt ngang.

\section{Các bước tiến hành nghiên cứu}

Khám lâm sàng

-Tuổi, giới, BMI (đánh giá BMI theo WHO dành cho người trưởng thành châu $A$ )

- Tiền sữ: thời gian mắc bệnh BPTNMT (được chẩn đoán), sử dụng thuốc corticosteroid (đường dùng, thời gian).

- Tiền sử hút thuốc lá: quy đổi ra đơn vị gói-năm.

Cận lâm sàng

* Đo chức năng hô hấp: FEV1/FVC, FEV1, test phục hồi phế quản

* Đo mật độ xương theo phương pháp DEXA và đánh giá mật độ xương theo WHO 1994 (các biến số BMD, T-score, Z-score) [3]. 


\begin{tabular}{|l|l|}
\hline \multicolumn{1}{|c|}{ Chẩn đoán } & \multicolumn{1}{c|}{ Tiêu chuẩn } \\
\hline - Bình thường & $\mathrm{T}>-1$ \\
\hline - Thiếu xương & $-2,5<\mathrm{T} \leq-1$ \\
\hline - Loãng xương & $\mathrm{T} \leq-2,5$ \\
\hline - Loãng xương nặng & Loãng xương + tiền sử gãy xương gần đây \\
\hline
\end{tabular}

Phương pháp xử lý số liệu

Tất cả các dữ liệu nhập vào đều được xử lý bằng máy vi tính, dựa vào chương trình phần mềm thống kê SPSS.

\section{KẾT QUẢ NGHIÊN CỬU}

Bảng 3.1. Mật độ xương nhóm nghiên cứu và phân bố mật độ xương theo một số đặc điểm nghiên cứu

\begin{tabular}{|c|c|c|c|c|}
\hline Đặc điểm & $\mathbf{N}$ & $\mathbf{\%}$ & $\mathbf{B M D}\left(\mathbf{g} / \mathbf{c m}^{\mathbf{2}}\right)$ & \multirow{2}{*}{$\mathbf{p}$} \\
\hline Bình thường & 12 & 28,57 & $0,568 \pm 0,111$ & \multirow{2}{*}{$<0,001$} \\
\hline Thiếu xương & 9 & 21,43 & $0,415 \pm 0,080$ & \\
\hline Loãng xương & 21 & 50 & $0,258 \pm 0,120$ & \\
\hline Tổng & $\mathbf{4 2}$ & $\mathbf{1 0 0}$ & $\mathbf{0 , 3 8 0} \pm \mathbf{0 , 1 7 3}$ & \\
\hline
\end{tabular}

Bảng 3.2. Bệnh nhân BPTNMT loãng xương 50\%, có sự khác biệt rõ rệt mật độ xương trong 3 nhóm bệnh nhân.

\begin{tabular}{|c|c|c|c|c|c|c|c|}
\hline \multirow{3}{*}{ Đặc điểm } & \multicolumn{6}{|c|}{ Mật độ xương } & \multirow{3}{*}{$\mathbf{p}$} \\
\hline & \multicolumn{2}{|c|}{ Bình thường } & \multicolumn{2}{|c|}{ Thiếu xương } & \multicolumn{2}{|c|}{ Loãng xương } & \\
\hline & $\mathrm{N}(12)$ & $28,57 \%$ & $\mathrm{~N}(9)$ & $21,43 \%$ & $\mathrm{~N}(21)$ & $50,0 \%$ & \\
\hline \multicolumn{8}{|l|}{ Độ tuổi } \\
\hline$<60$ & 5 & 11,90 & 2 & 4,76 & 0 & 0 & \multirow{4}{*}{0,005} \\
\hline $60-69$ & 2 & 4,76 & 5 & 11,90 & 2 & 4,76 & \\
\hline $70-79$ & 3 & 7,14 & 0 & 0 & 10 & 23,81 & \\
\hline$\geq 80$ & 2 & 4,76 & 2 & 4,76 & 9 & 21,43 & \\
\hline \multicolumn{8}{|l|}{ BMI } \\
\hline$<18.5$ & 1 & 2,38 & 2 & 4,76 & 11 & 26,19 & \multirow{3}{*}{0,001} \\
\hline $18.5-22.9$ & 9 & 21,43 & 5 & 11,90 & 9 & 21,43 & \\
\hline$\geq 23$ & 2 & 4,76 & 2 & 4,76 & 1 & 2,38 & \\
\hline \multicolumn{8}{|l|}{ Thời gian mắc } \\
\hline$<2$ năm & 6 & 14,28 & 2 & 4,76 & 2 & 4,76 & \multirow{3}{*}{0,002} \\
\hline 2- 5 năm & 5 & 11,90 & 7 & 16,16 & 8 & 19,05 & \\
\hline >5 năm & 1 & 2,38 & 0 & 0 & 11 & 26,19 & \\
\hline \multicolumn{8}{|l|}{ Hút thuốc lá } \\
\hline 20-30 gói-năm & 0 & 0 & 1 & 2,38 & 4 & 9,52 & \multirow{3}{*}{0,015} \\
\hline 31-40 gói-năm & 3 & 7,14 & 0 & 0 & 6 & 14,28 & \\
\hline >40 gói-năm & 9 & 21,43 & 8 & 19,05 & 11 & 26,19 & \\
\hline \multicolumn{8}{|c|}{ Sử dụng corticoid } \\
\hline Tại chổ & 10 & 23,81 & 5 & 11,90 & 2 & 4,76 & \multirow{2}{*}{$<0,001$} \\
\hline Toàn thân & 2 & 4,76 & 4 & 9,52 & 19 & 45,24 & \\
\hline
\end{tabular}




\begin{tabular}{|lcccccc|c|}
\hline Giai đoạn 1 & 2 & 4,76 & 1 & 2,38 & 0 & 0 & \\
Giai đoạn 2 & 9 & 21,42 & 7 & 16,16 & 11 & 26,19 & \multirow{2}{*}{0,003} \\
Giai đoạn 3 & 1 & 2,38 & 1 & 2,38 & 10 & 23,81 & \\
Giai đoạn 4 & 0 & 0 & 0 & 0 & 0 & 0 & \\
\hline
\end{tabular}

Có sự khác biệt về mật độ xương trong các nhóm biến tuổi, BMI, thời gian mắc, hút thuốc lá, sử dụng corticoid và $\mathrm{FEV} 1$

Bảng 3.3. Liên quan giữa mật độ xương với tuổi và sử dụng corticosteroid

\begin{tabular}{|c|c|c|c|c|c|}
\hline Giới & n & BMD $\left(\mathbf{g} / \mathbf{c m}^{\mathbf{2}}\right)$ & $\mathbf{p}$ & T-score & $\mathbf{p}$ \\
\hline Nữ & 11 & $0,188 \pm 0,086$ & $<0,001$ & $-4,2 \pm 0,9$ & $<0,001$ \\
\cline { 1 - 2 } & 31 & $0,448 \pm 0,141$ & & $-1,6 \pm 1,8$ & \\
\hline
\end{tabular}

Bảng 3.4. Có sự khác biệt có ý nghĩa thống kê về mật độ xương giữa 2 giới

\begin{tabular}{|c|c|c|c|c|c|}
\hline Sử dụng corticoid & $\mathbf{n}$ & $\mathbf{B M D}\left(\mathbf{g} / \mathbf{c m}^{\mathbf{2}}\right)$ & $\mathbf{p}$ & T-score & p \\
\hline Tại chỗ & 17 & $0,560 \pm 0,136$ & \multirow{2}{*}{$<0,001$} & $-0,6 \pm 1,5$ & \multirow{2}{*}{$<0,001$} \\
\cline { 1 - 2 } & 25 & $0,292 \pm 0,136$ & & $-3,5 \pm 1,3$ & \\
\hline Toàn thân & 25 &
\end{tabular}

Có sự khác biệt có ý nghĩa thống kê giữa về mật độ xương giữa 2 nhóm sử dụng và không sử dụng corticoi.

Tương quan giữa mật độ xương với tuổi, BMI

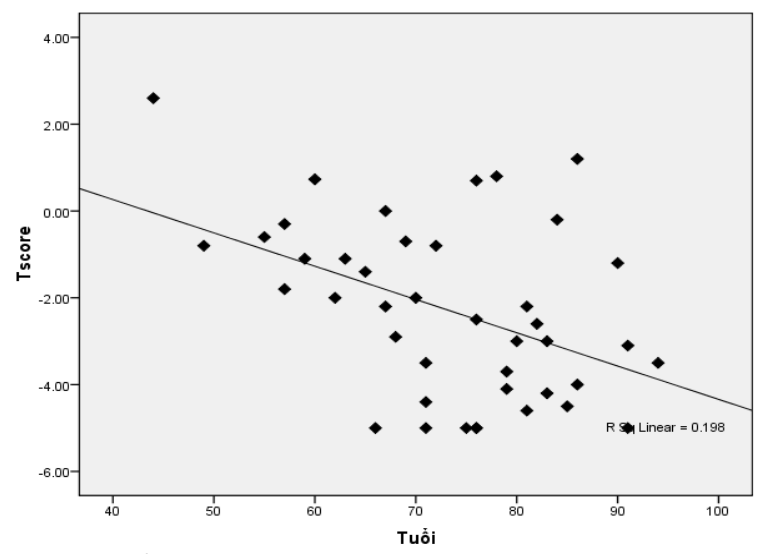

Mật độ xuoong và tuổi có sụ tương quan nghịch vìa $(\mathrm{r}=-0,445 ; \mathrm{p}=0,003)$

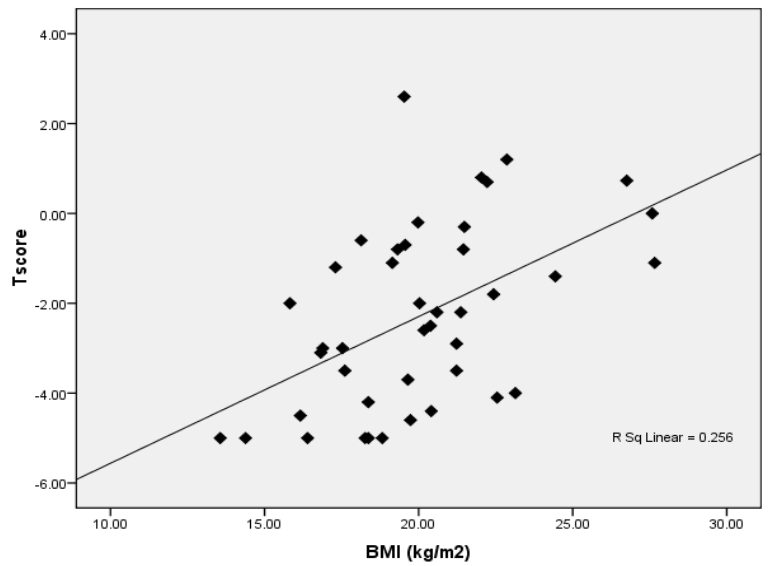

Mật độ xuơng và BMI có mối tương quan thuận vùa $(\mathrm{r}=0,506 ; \mathrm{p}<0,001)$ 


\section{Tưong quan giữa mật độ xưong với thời gian mắc BPTNMT}

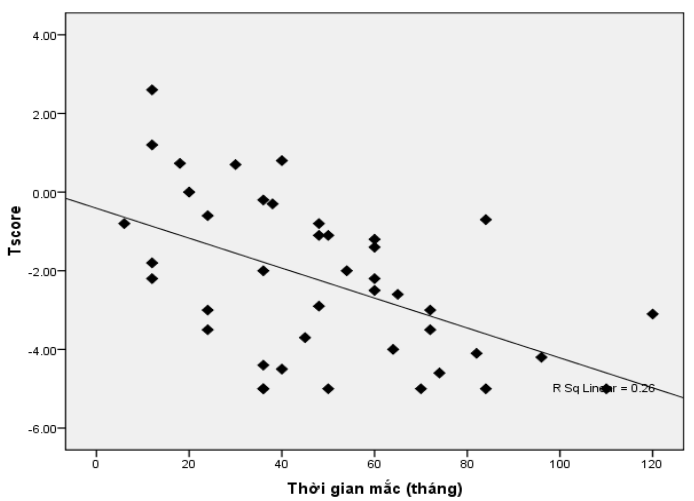

Mật độ xương có mối tương quan nghịch vìa với thời gian mắc bệnh $(\mathrm{r}=-0,510 ; \mathrm{p}<0,001)$

\section{Tương quan giữa mật độ xương với hút thuốc lá.}

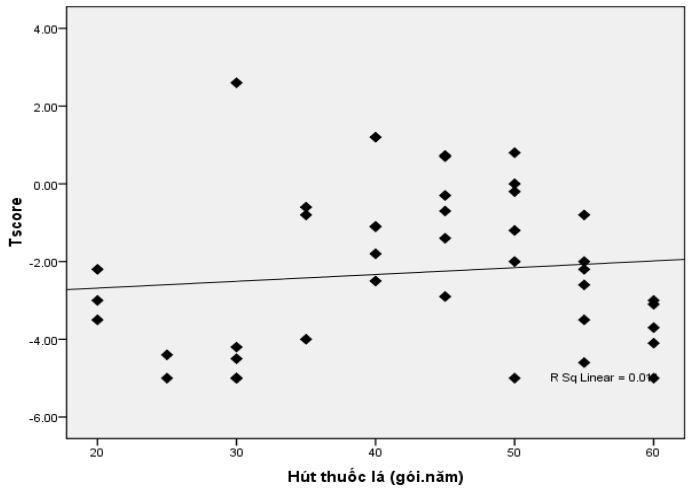

Chưa có sụ tương quan giũa mật độ xương với hút thuốc lá $(\mathrm{r}=0,106 ; \mathrm{p}=0,253)$

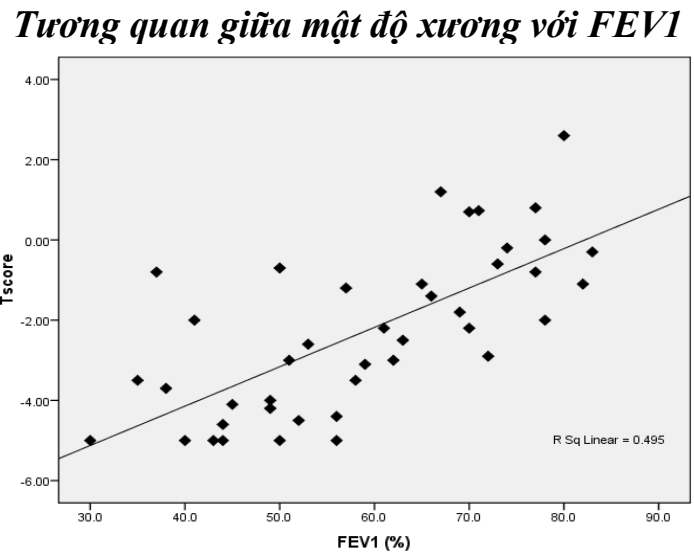

Mật độ xưong có mối tương quan thuận chặt với FEV1 ( $\mathrm{r}=0,704 ; \mathrm{p}<0,001)$

\section{BÀN LUẬN}

Kết quả nghiên cứu chúng tôi chỉ ra bệnh nhân BPTNMT loãng xương chiếm tỷ lệ cao nhất $(50 \%)$, thiếu xương $(21,43 \%)$, bình thường $(28,57 \%)$.Kết quả này của chúng tôi cũng phù hợp với các nghiên cứu khác. 
Theo Incalzi và cộng sự, nghiên cứu trên 104 bệnh nhân BPTNMT đang điều trị thì tỷ lệ loãng xương chiếm $60 \%$ [4].

Một nghiên cứu ở Ân Độ được thực hiện trên 108 bệnh nhân BPTNMT cũng cho thấy tỷ lệ loãng xương cao lên đến $66,6 \%$. Tác giả cũng kết luận rằng BPTNMT càng nặng thì nguy cơ loãng xương càng cao[5].

Phân tích gộp của tác giả Inoue và cộng sự từ 13 nghiên cứu khác nhau với 775 bệnh nhân cho kết quả giảm mật độ xương trung bình $35,1 \%(8,7-69 \%)[6]$.

Một nghiên cứu được công bố trên tạp chí nổi tiếng Chest (2009) thực hiện ở 88 trung tâm với 659 bệnh nhân cho kết quả $18 \%$ bệnh nhân nam, $30 \%$ bệnh nhân nữ được xác định loãng xương. Trong khi đó con số thiếu xương tương ứng là $42 \%$ nam so với $41 \%$ nữ.

Mật độ xương giảm trên bệnh nhân BPTNMT do nhiều yếu tố như hút thuốc lá, BMI thấp, thiếu vitamin $\mathrm{D}$, dinh dưỡng kém, giảm vận dộng, suy sinh dục và đặc biệt là sử dụng corticoid.

Khi phân tích mối liên quan chúng tôi nhận thấy giữa 2 nhóm $\mathrm{BMI}$ này có sự khác biệt rõ rật về mật độ xương.Một nghiên cứu của tác giả ở Iran cho thấy những nam giới có $\mathrm{BMI}<25$ có nguy cơ thiếu xương gấp 2,2 lần, loãng xương gấp 4,4 lần so với những nam giới có $\mathrm{BMI}$ từ 25 trở lên. Nghiên cứu khác thực hiện trên 393 phụ nữ mãn kinh, tác giả nhận thấy phụ nữ có cân nặng bình thường nguy cơ thiếu xương gấp 1,2 lần, nguy cơ loãng xương gấp 2 lần so với phụ nữ thừa cân béo phì.Từ kết quả các nghiên cứu trên có thể cho thấy BMI là một yếu tố nguy cơ của loãng xương[7].

Một nghiên cứu ở nam giới trung niên Hàn Quốc, tác giả kết luận rằng hút thuốc trên 30 gói-năm làm giảm mật độ xương. Trong một phân tích gộp từ 86 nghiên cứu trên thế giới, người hút thuốc lá giảm mật độ xương trên tất cả các vị trí đo so với người không hút thuốc hoặc đã từng hút thuốc.Như vậy hút thuốc lá làm giảm mật độ xương, nó tác động vào cơ chế chuyển hóa của xương như: thay đổi một số hormon chuyển hóa canxi và hấp thụ canxi từ ruột; rối loạn điều hòa chuyển hóa của một số hormon sinh dục; thay đổi chuyển hóa hormon thượng thận, hệ thống hoạt hóa receptor của yếu tố nhân kappa-B (RANK RANKL). Các cơ chế trên sẽ thay đổi ngược lại nếu bệnh nhân ngưng hút thuốc[8].

Khi phân tích về ảnh hưởng của đường dùng corticoid lên loãng xương của bệnh nhân BPTNMT sau khi điều chỉnh một số yếu tố chúng tôi thấy dạng hít làm giảm nguy cơ loãng xương 95,8 \% (OR 0,042; 95\% CI: 0,007-0,239; $\mathrm{p}<0,001)$. Dạng hít được sử dụng trong BPTNMT từ mức độ vừa đến nặng để làm giảm tần suất đợt cấp và cải thiện chất lượng cuộc sống. Dạng toàn thân được sử dụng khi nhập viện cải thiện sớm chức năng phổi. Một phân tích gộp gồm từ 16 nghiên cứu ngẫu nhiên có đối chứng và 7 nghiên cứu quan sát cho kết quả corticoid dạng hít làm tăng $27 \%$ nguy cơ gãy xương do loãng xương. Ảnh hưởng lên mật độ xương của corticoid dạng hít phụ thuộc liều sử dụng. Sử dụng dạng hít liều cao làm tăng 68\% nguy cơ gãy xương không đốt sống.[9] Chúng tôi chưa tìm được nghiên cứu nào so sánh giảm mật độ xương bệnh nhân BPTNMT dùng corticoid tại chỗ và đường toàn thân. Một số nghiên cứu mới chỉ tập trung đánh giá tác động sử dụng corticoid bằng đường uống ở một số bệnh nhân bệnh cơ xương khớp.

Cơ chế gây giảm mật độ xương ở bệnh nhân điều trị với corticoid:

- Giảm tạo xương: thông qua ức chế hoạt động của tạo cốt bào, ức chế sản xuất IGF-1 và testosteron, gia tăng cơ chế tự chết theo chương trình (apoptosis)

- Gia tăng hủy xương: kích thích tạo hủy cốt bào, giảm tiết androgens estrogens thông qua ức chế tiết gonadotropin, tăng tiết PTH.

- Giảm hấp thu canxi ở ruột, tăng tiết canxi qua thận

Theo kết quả nghiên cứu, nhóm bệnh nhân của chúng tôi có FEV1>=30\% (không có bệnh nhân giai đoạn 4). Bệnh nhân loãng xương phần lớn có FEV1 30-80\%. Chúng tôi ghi nhận có sự khác biệt mật độ xương ở từng giai đoạn FEV1. Nghiên cứu thực hiện trên 456 nữ giới khỏe mạnh không hút thuốc lá, tác giả nhận thấy FEV1 tương quan với mật 
độ xương cổ xương đùi ở nữ giới tiền mãn kinh. Nghiên cứu khác lại thực hiện trên 146 nam, có mối liên hệ giữa FEV1 và mật độ xương, BMI và tuổi. [10] Ở chiều ngược lại, nghiên cứu thực hiện năm 2013 trên 985 người độ tuổi từ 60-72 tuổi. Tác giả chưa thấy mối liên hệ nào giữa chức năng hô hấp và khối lượng xương trong cộng đồng. [11]

Một nghiên cứu thực hiện trên 115 bệnh nhân BPTNMT có FEV1 dưới $80 \%$. Tác giả nhận thấy bệnh nhân $\mathrm{FEV} 1<30 \%$ nguy cơ loãng xương gấp 7,6 lần so với bệnh nhân có FEV1 từ 50-80\% [12]

\section{KẾT LUẬN}

Qua nghiên cứu mật độ xương ở 42 bệnh nhân bệnh phổi tắc nghẽn mãn tính chúng tôi nhận thấy có $28,57 \%$ bình thường, $21,43 \%$ thiếu xương và $50 \%$ loãng xương. Mật độ xương liên quan và tương quan với giới, tuổi, tình trạng sử dụng corticoid, BMI, thời gian mắc và $\mathrm{FEV1}$. Chưa tìm thấy sự tương quan giữa mật độ xương với mức độ hút thuốc lá.

\section{TÀI LIÊU THAM KHẢO}

1. Regional COPD Working Group (2003), COPD prevalence in 12 Asia-Pacific countries and regions: Projections based on the COPD prevalence estimation model. Respirology, 8: 192-198

1. Masi L. (2008), Clinical Cases in Mineral and Bone Metabolism. Epidemiology of osteoporosis , 5(1):11-13.

2. Kanis JA, Melton LJ 3rd, Christiansen C, Johnston CC, Khaltaev N (1994). The diagnosis of osteoporosis. J Bone Miner Res 9:1137-1141.

3. Incalzi RA, Caradonna P, Ranieri $\mathrm{P}(2000)$, Correlates of osteoporosis in chronic obstructive pulmonary disease. Respir Med. 94(11):1079-84

4. Hattiholi, J., \& Gaude, G. S. (2014). Prevalence and correlates of osteoporosis in chronic obstructive pulmonary disease patients in India. Lung India: Official Organ of Indian Chest Society, 31(3), 221-227.

5. Inoue, D., Watanabe, R., Okazaki, R. (2016). COPD and osteoporosis: links, risks, and treatment challenges. International Journal of Chronic Obstructive Pulmonary Disease, 11, 637-648.

6. Salamat, M. R., Salamat, A. H., Abedi, I., \& Janghorbani, M. (2013). Relationship between Weight, Body Mass Index, and Bone Mineral Density in Men Referred for Dual-Energy X-Ray Absorptiometry Scan in Isfahan, Iran. Journal of Osteoporosis, 2013, 205963.

7. Ward, K. D., \& Klesges, R. C. (2001). A Meta-Analysis of the Effects of Cigarette Smoking on Bone Mineral Density. Calcified Tissue International, 68(5), 259-270.

8. Chee, C., Sellahewa, L., \& Pappachan, J. M. (2014). Inhaled Corticosteroids and Bone Health. The Open Respiratory Medicine Journal, 8, 85-92.

9. Watanabe R, Tanaka T, Aita K. (2015), Osteoporosis is highly prevalent in Japanese males with chronic obstructive pulmonary disease and is associated with deteriorated pulmonary function. $J$ Bone Miner Metab, 33(4):392-400

10. Dennison, E., Dhanwal, D., Shaheen, S., (2013). Is lung function associated with bone mineral density? Result from Hertfordshire cohort study. Archives of osteoporosis, 8(0), 115.

11. Vrieze M. H. G. de Greef, Wýkstra P. J. (2007), Low bone mineral density in COPD patients related to worse lung function, low weight and decreased fatfree mass, Osteoporosis Int, 18:11971202. 